УДК 547.27.

ПОЛУЧЕНИЕ ПЕРСПЕКТИВНЫХ КИСЛОРОДОСОДЕРЖАЩИХ КОМПОНЕНТОВ МОТОРНЫХ ТОПЛИВ

\title{
OBTAINING PROMISING OXYGEN-CONTAINING COMPONENTS OF MOTOR FUELS
}

Кэ Пэн (Китайская Народная Республика), Якупов Н.В., Гаеткулова Г.К., Рахимов М.Н., Давлетшин А.Р., Хамзин Ю.А., Шириязданов Р.Р. Уфимский государственный нефтяной технический университет, г. Уфа, Российская Федерация

Ke Peng (People's Republic of China), Nail V. Yakupov, Gulshat K. Gayetkulova, Marat N. Rakhimov, Artur R. Davletshin, Yunir A. Khamzin, Rishat R. Shiriyazdanov Ufa State Petroleum Technical University, Ufa, Russian Federation e-mail: 1026928674@qq.com

Аннотация. В работе представлены результаты синтеза таких перспективных кислородосодержащих компонентов моторных топлив, как дибутиловый эфир и диэтиловый эфир на сульфокафтионитном катализаторе КУ-2ФПП и цеолитсодержащем катализаторе LaH-USY.

Хроматографическим методом анализа исследовано влияние различных показателей процесса на состав продуктов этерификации, выход целевого продуктов и определены оптимальные условия.

Установлено, что оптимальной температурой процесса этерификации и объёмной скоростью подачи сырья на катализаторах КУ-2ФПП и LaH-USY является $90{ }^{\circ} \mathrm{C}$ и 1 ч $^{-1}$ соответственно. Максимальный выход дибутилового эфира при данных параметрах на катализаторе КУ-2ФПП составил 10,24 $\%$ масс. При аналогичных условиях на образце цеолитсодержащего 
катализатора LaH-USY выход составил 30,02\% масс. Для синтеза дибутилового и диэтиловый эфиров методом междумолекулярной дегидратации цеолитсодержащий катализатор LaH-USY показывает лучшие каталитические свойства, чем КУ-2ФПП и является более предпочтительным с точки зрения возможного применения.

Abstract. The paper presents the synthesis results of such promising oxygen-containing components of motor fuels as dibutyl ether and diethyl ether on the KU-2FPP sulfo-naphthionite catalyst and the LaH-USY zeolitecontaining catalyst.

The chromatographic method of analysis investigated the effect of various process indicators on the composition of the esterification products, the yield of the target products, and optimal conditions were determined.

It has been established that the optimal temperature of the esterification process and the bulk feed rate of the catalysts KU-2FPP and LaH-USY is $90{ }^{\circ} \mathrm{C}$ and $1 \mathrm{~h}^{-1}$, respectively. The maximum yield of dibutyl ether with these parameters on the catalyst KU-2FPP was $10.24 \%$ by weight. Under similar conditions on the sample zeolite-containing catalyst LaH-USY, the yield was $30.02 \%$ of the mass. For the synthesis of dibutyl and diethyl ethers by the method of intermolecular dehydration, the zeolite-containing catalyst LaH-USY shows better catalytic properties than KU-2FPP and is more preferable from the point of view of possible application.

\section{摘要}

本文介绍了使用磺基阳离子交换树脂 KU-2FPP 和沸石型分子篮 $\mathrm{LaH}-$ USY 作为催化剂合成有前景的可作为发动机燃料的含氧组分二丁醚（DBE） 的结果。运用色谱分析方法研究了各种工艺指标对酯化产物的组成和目标 产物的产率的影响及其确定了生产的最佳条件。 
Ключевые слова: этерификация, кислородосодержащий компонент, дибутиловый эфир, цеолит, сульфокатионитный катализатор

Key words: esterification, oxygen-containing component, dibutyl ether, zeolite, sulfo-naphthionite catalyst

关键词 : 醚化反应, 含氧组分, 正丁醚, 沸石, 磺基阳离子交换树脂催 化剂

\section{Введение}

В настоящее время в нефтеперерабатывающей и нефтехимической отраслях особое внимание уделяется защите окружающей среды. Производство экологически чистых компонентов современных автобензинов позволяет получать товарные топлива, соответствующие современным экологическим стандартам. Перспективным направлением является синтез кислородсодержащих соединений как компонентов бензинов. Простые эфиры обладают рядом преимуществ по сравнению со спиртами, которые характеризуются фазовой нестабильностью, коррозионной активностью и невысоким значением удельной теплоты сгорания.

Основными свойствами простых эфиров являются: хорошая совместимость, высокое значение октанового числа, меньшая гигроскопичность, меньшая коррозионная активность [1]. В последние годы проявляется большой интерес к дибутиловому эфиру (ДБЭ) и диэтиловому эфиру (ДЭЭ) как компонентам моторных топлив.

Традиционно в качестве высокооктанового компонента получают метил-трет-бутиловый эфир, однако его применение во многих странах ограничено вследствие его токсичности. 
Особый интерес к дибутиловому и диэтиловому эфирам объясняется тем, что в последние годы разработаны новые технологии получения симметричных эфиров [2-4].

Классическим методом синтеза симметричных простых эфиров является метод межмолекулярной дегидратации спиртов в присутствии кислотных катализаторов. Синтез асимметричных эфиров проводят по реакции бимолекулярного нуклеофильного замещения (реакция Вильямсона) [5].

В качестве катализаторов реакции этерификации используют серную кислоту, неорганические соли, оксиды металлов, ионнообменные смолы, цеолиты, природные глины, гетерополикислоты [6].

Процесс получения диэтилового эфира реакцией межмолекулярной дегидратации этанола проводят в присутствии серной кислоты при температуре от $130{ }^{\circ} \mathrm{C}$ до $170{ }^{\circ} \mathrm{C}$. Установлено, что максимальный выход целевого продукта составляет почти 70,0 \% масс. при температурах $135-145^{\circ} \mathrm{C}$, однако применение серной кислоты ограничено вследствие ее высокой коррозионной активности и токсичности [7].

Перспективными катализаторами получения симметричных эфиров являются сульфокатиониты и цеолиты. Процесс получения метил-третбутилового эфира (МТБЭ) хорошо изучен в работе [8], где представлены результаты синтеза МТБЭ реакцией межмолекулярной дегидратации метилового и изобутилового спиртов с использованием в качестве катализаторов сульфокатионитов (Amberlyst-35 и Dandong-A330).

Установлено, что в течение 4782 ч в процессе этерификации с использованием катализатора Dandong-A330 конверсия изобутилового спирта увеличивается от 49,7 \% масс. до 53,7 \% масс., а селективность по целевому продукту изменяется от 87,2 \% масс. до 90,9 \% масс.

В процессе этерификации спиртов на катализаторе Amberlyst-35 в течение 3230 ч конверсия изобутилового спирта увеличивается от $52,3 \%$ масс. до 55,4\% масс. 
В работе [9] представлены результаты получения ДЭЭ с использованием в качестве катализатора цеолита ZSM-5, промотированного катионами $\mathrm{Ti}^{4+}$.

Катализатор TiZSM-5 получали методом пропитки исходного цеолита ZSM-5 раствором $\mathrm{Ti}\left(\mathrm{SO}_{4}\right)_{2}$ при нагревании в течение в течение 2 ч. В процессе получения ДЭЭ установлено, что максимальный выход целевого продукта 73,0 \% масс. наблюдается при температуре $162{ }^{\circ} \mathrm{C}$, объемной скорость подачи сырья 1,66 ч $^{-1}$ и концентрации $\mathrm{Ti}\left(\mathrm{SO}_{4}\right)_{2}$ равной 0,05 моль/л.

В настоящей работе представлены результаты синтеза дибутилового эфира с использованием сульфокатионита КУ-2ФПП и цеолитсодержащего катализатора LaH-USY в качестве катализаторов.

\section{Экспериментальная часть}

Процесс этерификации бутилового спирта проводили с использованием промышленного катализатора КУ-2ФПП и синтезированного ранее цеолитсодержащего катализатора LaH-USY на лабораторной установке с объемом реактора $15 \mathrm{~cm}^{3}$.

Исследования проводились при давлении в реакторе 0,1 МПа, в интервале температур 70-110 ${ }^{\circ} \mathrm{C}$, объемная скорость подачи бутанола составляла 1-2 ч ${ }^{-1}$.

Состав полученных продуктов реакции определяли на хроматографе с пламенно-ионизационным детектором и высокоэффективной капиллярной колонкой типа HP-1 (DB-1) 50 м X 0,21 мм X 0,5 мкм.

\section{Синтез катализатора LaH-USY}

Образец катализатора получают последовательными стадиями ионного обмена цеолита Na-Y в растворе сульфата аммония и нитрата лантана, термической обработкой и ионного обмена в растворе смеси нитрата лантана и сульфата аммония (рисунок 1). 


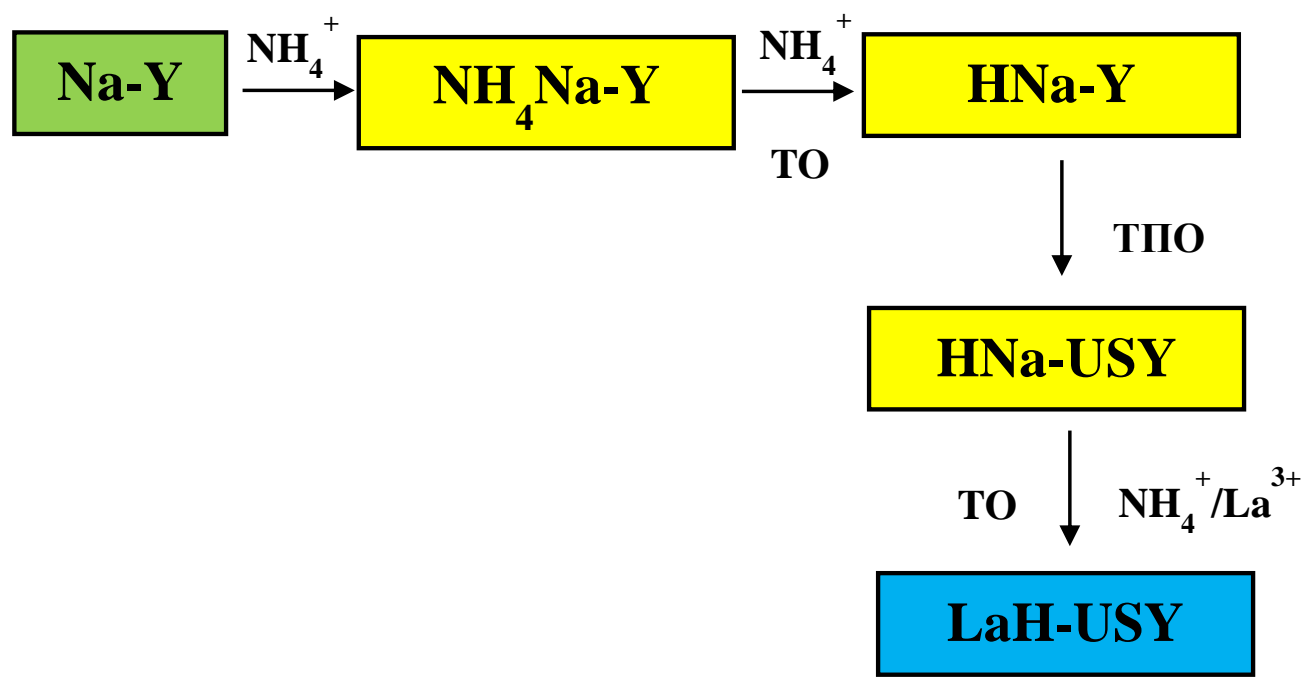

Рисунок 1. Блок-схема получения катализатора LaH-USY.

Первый ионныци обмен на $\mathrm{NH}_{4}^{+}$и $\mathrm{La}^{3+}$ проводят при постоянном перемешивании в растворе, содержащем смесь 0,1 М нитрата лантана и 0,75 М сульфата аммония, при температуре $70-80{ }^{\circ} \mathrm{C}$ в течение 1 ч. Соотношение объема раствора к массе исходного цеолита составляет 10 мл/г. Полученный продукт также фильтруют и промывают дистиллированной водой, предварительно подогретой до $60{ }^{\circ} \mathrm{C}$. Затем полученная лепешка катализатора сушится при температуре $120{ }^{\circ} \mathrm{C}$ в течение 4 ч.

Перед последующей операцией ионного обмена проводится термообработка при температуре $550{ }^{\circ} \mathrm{C}$ в течение 3 ч. Скорость нагрева должна не превышать $10{ }^{\circ} \mathrm{C} / \mathrm{мин.}$

Следующая стадия ионного обмена проводится также в растворе 0,1 M нитрата лантана и $0,75 \mathrm{M}$ сульфата аммония при температуре $70-80{ }^{\circ} \mathrm{C}$ в течение 1 ч.

После завершения стадий обмена полученный продукт фильтруют и промывают водой, подогретой до $60{ }^{\circ} \mathrm{C}$. На 1 г полученного цеолита необходимо 6 мл дистиллированной воды.

Далее полученная лепешка цеолита в течение 4 ч сушится при температуре $120^{\circ} \mathrm{C}$. 


\section{Обсуждение экспериментальных данных}

На первом этапе исследовалось влияние температуры процесса и объёмной скорости подачи сырья на выход дибутилового эфира в процессе этерификации бутанола на катализаторе КУ-2ФПП.

На рисунке 2 представлено полученное по результатам эксперимента влияние температуры процесса этерификации на выход дибутилового эфира при различных объемных скоростях подачи сырья $\left(1 ; 1,5\right.$ и 2 ч $\left.^{-1}\right)$.

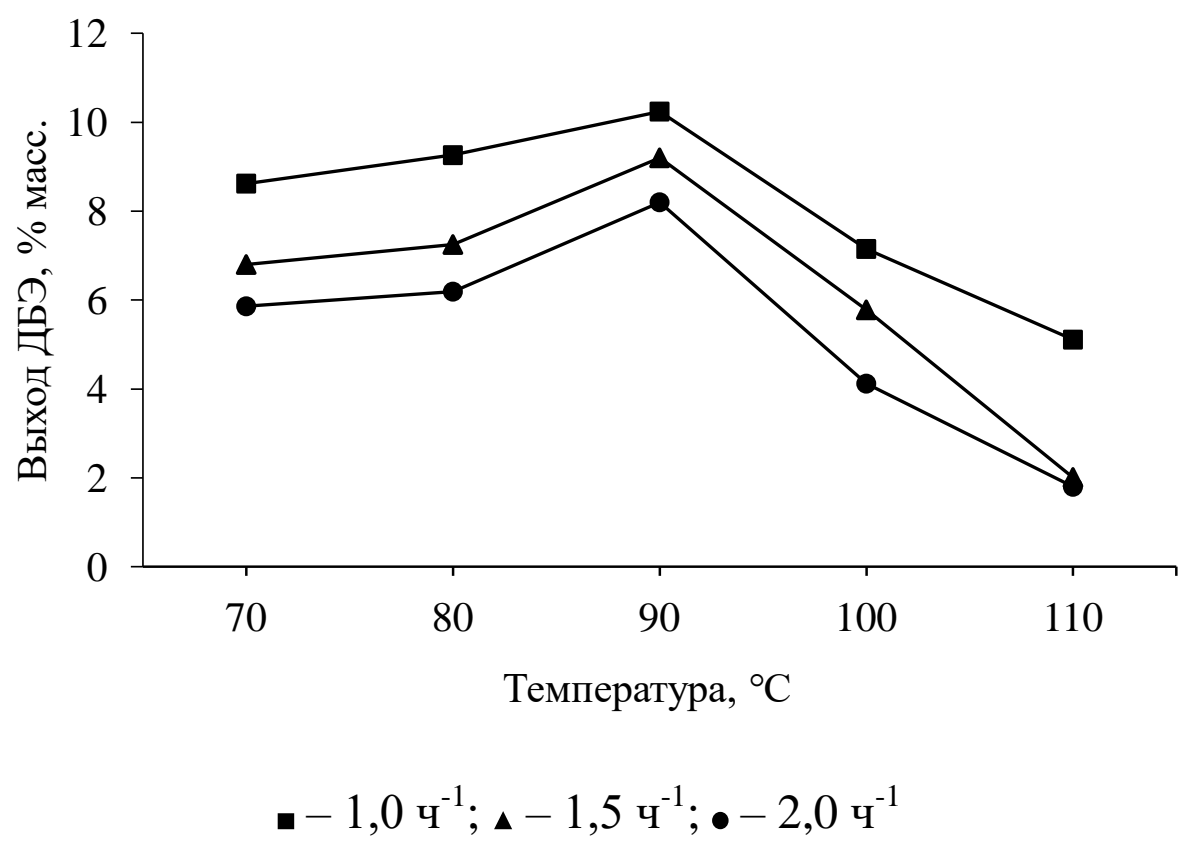

Рисунок 2. Зависимость выхода ДБЭ от температуры процесса этерификации на КУ-2ФПП

Исследованиями влияния температуры на реакцию этерификации установлено, что увеличение температуры от $70{ }^{\circ} \mathrm{C}$ до $90{ }^{\circ} \mathrm{C}$ приводит к увеличению выхода целевого продукта с 8,62 \% масс. до 10,24 \% масс. (объемная скорость подачи сырья - 1,0 ч ${ }^{-1}$ ). Это связано с ростом скорости реакции межмолекулярной дегидратации бутилового спирта. Последующее увеличение температуры процесса до $110{ }^{\circ} \mathrm{C}$ приводит к снижению выхода ДБЭ до 5,11 \% масс. 
В экзотермической реакции увеличение температуры сдвигает химическое равновесие в сторону исходных компонентов, что приводит к снижению выхода целевого продукта. Аналогичные закономерности изменения выходов ДБЭ наблюдаются и при объемной скорости подачи сырья равной 1,5 и 2,0 ч ${ }^{-1}$. Выход ДБЭ с увеличением температуры этерификации от $70{ }^{\circ} \mathrm{C}$ до $90{ }^{\circ} \mathrm{C}$ изменяется от 6,80 \% масс. до 9,20\% масс. и с 5,86 \% масс. до 8,20\% масс. соответственно. Дальнейшее увеличение температуры реакции до $110{ }^{\circ} \mathrm{C}$ приводит к снижению выхода до $2,01 \%$ масс. и $1,8 \%$ масс. соответственно.

Таким образом, максимальный выход дибутилового эфира наблюдается при температуре $90{ }^{\circ} \mathrm{C}$ и объемной скорости подачи сырья $1 \mathrm{ч}^{-1}$.

На следующем этапе исследовано влияния температуры и объемной скорости подачи сырья на выход целевых продуктов в процессе этерификации бутанола с использованием в качестве катализатора цеолитсодержащего образца LaH-USY.

На рисунке 3 представлены зависимости выхода дибутилового эфира от температуры процесса этерификации бутанола-1 при различных объемных скоростях подачи сырья (1; 1,5 и 2 ч $\left.^{-1}\right)$.

Изменение температуры процесса этерификации от $70{ }^{\circ} \mathrm{C}$ до $90{ }^{\circ} \mathrm{C}$ при различных объёмных скоростях подачи сырья $\left(1 ; 1,5\right.$ и 2 ч $\left.^{-1}\right)$ приводит к увеличению выхода целевого продукта с 17,80 \% масс. до 30,02\% масс., с $17,3 \%$ масс. до $28,36 \%$ масс. и с $15,60 \%$ масс. до $26,36 \%$ масс. соответственно.

Последующее увеличение температуры процесса до $110{ }^{\circ} \mathrm{C}$ приводит к снижению выхода дибутилового эфира до 24,14 \% масс., 21,67 \% масс. и $18,63 \%$ масс. соответственно. Установлено, что максимальное значение выхода дибутилового эфира наблюдается при $90{ }^{\circ} \mathrm{C}$ и объемной скорости подачи бутанола $1 \mathrm{ч}^{-1}$. 


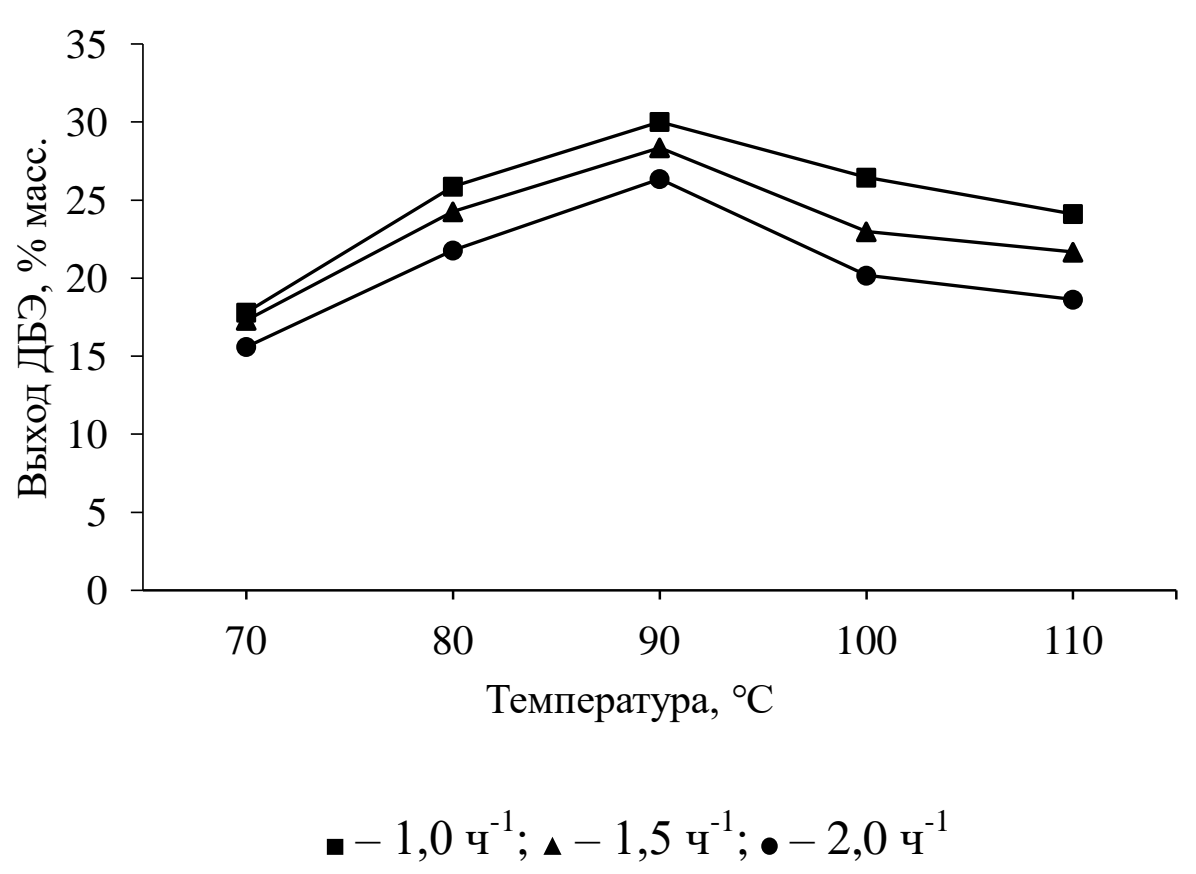

Рисунок 3. Зависимость выхода ДБЭ от температуры процесса этерификации на цеолитсодержащем катализаторе LaH-USY

\section{Выводы}

Установлено, что оптимальной температурой процесса этерификации и объёмной скоростью подачи сырья на катализаторах КУ-2ФПП и LaH-USY является $90{ }^{\circ} \mathrm{C}$ и 1 ч $^{-1}$ соответственно.

Максимальный выход дибутилового эфира при данных параметрах на катализаторе КУ-2ФПП составил 10,24 \% масс. При аналогичных условиях на образце цеолитсодержащего катализатора LaH-USY выход составил $30,02 \%$ масс.

Для синтеза дибутилового эфира методом междумолекулярной дегидратации цеолитсодержащий катализатор LaH-USY показывает лучшие каталитические свойства, чем КУ-2ФПП и является более предпочтительным с точки зрения возможного применения. 


\section{Список используемых источников}

1. Ахметов С.А. Технология глубокой переработки нефти и газа. Уфа: Изд-во «Гилем», 2013. 544 с.

2. Вангшенг У. Современная ситуация и тенденции развития присадок к бензину // Химическая промышленность Гуанчжоу. 2013. Т. 41. № 21. 33 с.

3. Матюшина P.Р., Шириязданов P.Р., Ахметов С.А., Давлетшин А.Р., Рахимов М.Н., Абдюшев Р.Р. Молекулярная дегидратация спиртов в топливные эфиры на цеолитах структуры FAU // Башкирский химический журнал. 2013. Т. 20. № 3. С. 48-51.

4. Шириязданов Р.Р., Давлетшин А.Р., Смирнов В.К., Кузнецов Е.В., Рахимов М.Н., Абрамов П.И., Ипатова Е.А. Получение этил-третбутилового эфира из биоспиртов на цеолитах // Башкирский химический журнал. 2011. Т. 18. № 2. С. 48-51.

5. Сюй Янмэй, Вэй Цзяньин, Хань Чжоусян. Синтез асимметрического эфира экологически чистым методом // Химическая промышленность Гуанчжоу. 2008. Т. 35. № 4. С. 21-22.

6. Ню Пинпин. Исследования по синтезу полиолеата: автореф. ... д-ра техн. наук. Китай, Университет Хунань, 2014.

7. Фэн Лу, Ян Ин. Обсуждение нового экспериментального устройства для одностадийного синтеза эфира // Гуандун Химическая промышленность. 2018. Т. 45. № 15.140 с.

8. Лу Кэпэнг. Изучение реакции этерификации на катализаторе на основе сильной кислоты: дисс. ... доктор. техн. наук. Китай, Даляньский технологический университет, 2016.

9. Хуан Ин, Чэнь Шоужен, Лин Шэн, Ван Вэньго, Ху Лимин, Янь Гуэйян. Дегидратация этанола в этиловый эфир при модификационном цеолите TiZSM-5 // Журнал университета учителей Фуцзяни. 1997. T. 13. № 2. C. 54-57. 


\section{References}

1. Akhmetov S.A. Tekhnologiya glubokoy pererabotki nefti $i$ gaza [Technology of Deep Refining of Oil and Gas]. Ufa, Gilem Publ., 2013. 544 p. [in Russian].

2. Wu Wangsheng. Sovremennaya situatsiya i tendentsii razvitiya prisadok k benzinu [Current Situation and Development Trend of Gasoline Additives]. Khimicheskaya promyshlennost' Guanchzhou - Guangzhou Chemical Industry, 2013, Vol. 41, No. 21, pp. 21-22.

3. Matyushina R.R. Shiriyzdanov R.R., Akhmetov S.A., Davletshin A.R., Rakhimov M.N., Abdyushev R.R. Molekulyarnaya degidratatsiya spirtov v toplivnyye efiry na tseolitakh struktury FAU [Molecular Dehydration of Alcohols in Fuel Esters on Zeolite Structure FAU]. Bashkirskiy khimicheskiy zhurnal Bashkirian Chemical Journal, 2013, Vol. 20, No. 3, pp. 48-51. [in Russian]

4. Shiriyzdanov R.R., Davletshin A.R., Smirnov V.K., Kuznetsov E.V., Rakhimov M.N., Abramov P.I., Ipatova E. Polucheniye etil-tret-butilovogo efira iz biospirtov na tseolitakh [A Getting Ethyl-Tret-Butyl Ether from Biospirtov on Zeolite]. Bashkirskiy khimicheskiy zhurnal - Bashkirian Chemical Journal, 2013, Vol. 18, No. 2, pp. 48-51. [in Russian]

5. Xu Yanmei, Wei Jianying, Han Zhouxiang. Sintez asimmetricheskogo efira ekologicheski chistym metodom [Synthesis of Asymmetry Ether by an Environment-Friend Method]. Khimicheskaya promyshlennost' Guanchzhou Guangzhou Chemical Industry, 2008, Vol.35, No. 4, pp. 21-22.

6. Niu Pingping. Issledovaniya po sintezu polioleata: avtoref. doktor. tekhn. nauk. [Studies on Synthesis of Polyol Oleate: Doc. Engin. Sci. Avtoref.]. China, Hunan University, 2014.

7. Feng Lu, Yang Ying. Obsuzhdeniye novogo eksperimental'nogo ustroystva dlya odnostadiynogo sinteza efira [Discussion on a New Experimental Device for One-Step Synthesis of Ether]. Guandun Khimicheskaya promyshlennost'- Guangdong Chemical Industry, 2018, Vol. 45, No. 15,140 p. 
8. Lu Kepeng. Izuchenie reaktsii eterifikatsii na katalizatore na osnove sil'noi kisloty: diss. doktor. tekhn. nauk. [Study on Esterification Reaction over Strong Acid Resin Catalyst: Doc. Engin. Sci. Avtoref.]. China, Dalian University of Technology, 2016.

9. Huang Ying, Chen Shouzheng, Lin Shen, Wang Wenguo, Hu limin, Yan guiyang. Degidratatsiya etanola v etilovyy efir pri modifikatsionnom tseolite TiZSM-5 [Ethanol Dehydration to Ethyl Ether Catalyzed by Molecular Sieve TiZSM-5]. Zhurnal universiteta uchiteley Futszyani - Journal of Fujian Teacher's University, 1997, Vol. 13, No. 2, pp. 54-57.

\section{Сведения об авторах}

\section{About the authors}

Кэ Пэн (Китайская Народная Республика), магистрант кафедры «Технология нефти и газа», УГНТУ, г. Уфа, Российская Федерация

Ke Peng (People's Republic of China), Undergraduate Student of Oil and Gas Technology Department, USPTU, Ufa, Russian Federation e-mail: 1026928674@qq.com

Якупов Наиль Владиславович, студент кафедры «Нефтехимия и химическая технология», УГНТУ, г. Уфа, Российская Федерация

Nail V. Yakupov, Student of Petrochemistry and Chemical Technology Department, USPTU, Ufa, Russian Federation

e-mail: nail.rahhhh@gmail.com

Гаеткулова Гульшат Камилевна, магистрант кафедры «Нефтехимия и химическая технология», УГНТУ, г. Уфа, Российская Федерация

Gulshat K. Gaetkulova, Undergraduate Student of Petrochemistry and Chemical Technology Department, USPTU, Ufa, Russian Federation e-mail: gulshat.gaetkulova@gmail.com 
Рахимов Марат Наврузович, д-р техн. наук, профессор кафедры «Технология нефти и газа», УГНТУ, г. Уфа, Российская Федерация

Marat N. Rakhimov, Doctor of Engineering Sciences, Professor of Oil and Gas Technology Department, USPTU, Ufa, Russian Federation e-mail:rmni@mail.ru

Давлетшин Артур Раисович, канд. техн. наук, доцент кафедры «Технология нефти и газа», УГНТУ, г. Уфа, Российская Федерация

Artur R. Davletshin, Candidate of Engineering Sciences, Associate Professor of Oil and Gas Technology Department, USPTU, Ufa, Russian Federation e-mail: davletshinar@list.ru

Хамзин Юнир Азаматович, ассистент кафедры «Газохимия и моделирование химико-технологических процессов», УГНТУ, г. Уфа, Российская Федерация

Yunir A. Khamzin, Assistant of Gas Chemistry and Modeling of ChemicalTechnological Processes Department, USPTU, Ufa, Russian Federation e-mail: Yunirkh@bk.ru

Шириязданов Ришат Рифкатович, д-р техн. наук, ведущий научный сотрудник Управления научных исследований и разработок, УГНТУ, г. Уфа, Российская Федерация

Rishat R. Shiriyazdanov, Doctor of Engineering Sciences, Leading Researcher of Research and Development Department, USPTU, Ufa, Russian Federation

e-mail: petroleum9@bk.ru 